\title{
Empirical Analysis of Factors Influencing Agricultural Insurance Coverage in China: A Supply and Demand Perspective
}

\author{
Xuan Zuo ${ }^{\text {b }}$, Qiao Zhang ${ }^{\text {a, * }}$ \\ Agricultural Information Institute of Chinese Academy of Agricultural Science, Beijing 100081, \\ China \\ a zhangqiao@caas.cn, b824659753@qq.com
}

Keywords: Supply, demand, agricultural insurance, level of protection, influencing factors, China.

\begin{abstract}
The cold facts of the supply and demand situation" for agricultural insurance guarantees in China are the key reasons for the current low levels of protection available. Through an analysis of economic principles and domestic and overseas research, we posit the factors influencing the level of agricultural insurance in China from the perspective of both supply and demand. Regression analysis is carried out using Stata13.0 software. The results indicate that government insurance subsidies, the level of social economic development, and farmers' production scale are the most significant factors with positive correlations affecting the supply and demand of agricultural insurance; moreover, the influence of the per capita net income of farmers is relatively significant and negatively correlated. Finally, from the perspective of supply and demand balance, insurance companies complying with the laws of the market should pursue the majority of the business to raise the level of agricultural insurance supply. The government should compensate for market failures and increase the premium subsidies. New agricultural business entities with large-scale production are the main source of the demand.
\end{abstract}

\section{Introduction}

Agricultural insurance in China has developed aggressively since China's central government subsidies implemented in 2004. During the 10 years, from 2007 to 2016, agricultural insurance liabilities in China increased from 112.6 billion yuan to 2.160 trillion yuan, with an average annual growth rate of 38.83\%. In concert, premium income increased from 5.180 billion yuan to 41.712 billion yuan, an increase of seven times; crop-covered areas extended from 230 million acres to 1.721 billion million acres, an increase of six times; and, the scale of China's agricultural insurance became the second largest in the world. In 2017, in the central government's document that focuses on the development of agricultural insurance, it points out that to: "continue to promote agricultural insurance products, expanding coverage, increasing the variety, upgrading the standards, and meeting the insurance products' development need of new agricultural business entities, takes the 'YiJiangDaiBu' way to support the local characteristics of agricultural products.”

The demand for agricultural insurance in foreign countries mainly focuses on the reasons why customers are not willing to buy it, the customer ability for self-insurance, substitutes, and moral hazard. AdeJanvrya et al. (2011) stressed the importance of the "free riding” phenomenon as a main reason for agricultural insurance coordination problems with farmers' choices. Sherrick et al. (2004) analyzed farmers' choices between agricultural insurance and other alternative products, and the results showed that farms with high-expected yield risks had higher demand for agricultural insurance. Saleem et al. (2005) researched the demand for crop insurance and whether the factors affecting farmers' selection of crop insurance were: initial wealth, the sign of risk aversion (positive/negative), the mean yield, the yield standard deviation, the average price, the price standard deviation, risk probability, irrigation ratio, and the decision to buy income insurance rather than the decision on the amount insurance. Based on an empirical analysis of farm soybean and corn data at the national level, Calvin and Quiggin (1999) concluded that farmers chose agricultural insurance mainly to receive subsidies or because of adverse selection and risk aversion, but the incentive effect was not large. For farmers in the United States, based on initial wealth, to a certain degree, the risk aversion weakens. 
Therefore, the motivation to purchase agricultural insurance is less. The United States Department of Agriculture did a national survey on why farmers did not participate in Federal Crop Insurance. Five reasons were identified: 1 . the guarantee was too low, 2. the premium was too high, 3 . they were willing to take more risk, 4 . farm management, and 5. had other scattered crop insurance. Those five reasons accounted for $84.9 \%$ of all reasons (Wright and Hewitt 1994).

Research on factors influencing agricultural insurance supply in foreign countries includes the following. Jerry et al. (2001) thought cooperation in agricultural insurance supply was the main factor influencing supply, and that as business insurance companies were the main suppliers of agricultural insurance, all business behavior should be based on the commercial insurance market. They also believed that the supply of agricultural insurance should be market-oriented, as government led agricultural insurance supply has the disadvantage of large inefficiency and transaction cost. Goodwin et al. (2001) thought the mode of supply was the primary factor affecting the agricultural insurance supply. Exploring the mode of agricultural insurance and its development through the historical process of a continuous cycle, they identified the following cycle: 1 . creation of a test, 2 . breed development, 3. breed maturity, 4. breed implementation, 5. lag behind, 6., elimination, and 7. breed again; incomplete market returns and complex transaction costs determine that the supply in the agricultural insurance should be market-oriented. Foreign scholars have focused on the study of the supply of agricultural insurance and shown the cooperation among the supply agents as the most important factor affecting the supply of agricultural insurance.

Many domestic scholars have analyzed the demand for agricultural insurance. In view of the low demand for agricultural insurance in China, counter measures to improve demand have been put forward. Based on field survey data of Hebei province, Li and Wang (2010) analyzed the current situation of agricultural insurance participation of farmers and found that farmer willingness to pay for agricultural insurance was not very strong. Using a logistic regression model, Wang et al. (2010) found that attitudes towards agricultural risk, the premiums, farmers' educational levels, income levels, risk types, and losses suffered were the main factors influencing farmer willingness to buy agricultural insurance in the counties of Henan province. After investigating 100 farmers in Wuhan and Xingshan counties, Chen et al. (2007) found that the main factors influencing willingness to purchase agricultural insurance were: household agricultural income, cultivated land area, farmers' years of education, and farmers years of farming.

Notably, farmers with a certain scale of operation were more inclined to purchase agricultural insurance. Thus, the implementation of agricultural insurance should be related to the scale and production of the agriculture operation. The combination of industry management and agricultural insurance should be strengthened at the same time. Zhang et al. (2007) analyzed the influencing factors of agricultural insurance demand at different levels in 11 villages among 662 farmers in the Henan province using questionnaires to carry out empirical research. The results show that education level, whether or not they work, and annual income were positively correlated to agricultural insurance participation; however, commercial agricultural insurance in China is still very difficult to launch.

Based on the growth of agricultural insurance as its goal, the Chinese government should expand the policy of agricultural insurance subsidies. Zhang et al. (2005) investigated the "supply and demand cold facts" in the agricultural insurance market in China. The problems with demand for agricultural insurance were interpreted based on first-hand data of Shanxi province and Jiangxi Province. Through field research and empirical analysis of farmer insurance preferences in two provinces, they indicated that increasing the farmers' choices of agricultural insurance could also increase their income. In economically underdeveloped areas, farmers are not inclined to use agricultural insurance to diversify their agricultural risks without subsidies from the government. Ning et al. (2005) examined cotton-planting households in the Manasi River Valley of Xinjiang. Their study analyzed the factors influencing cotton insurance under the condition of no subsidy, and found that factors such as specialty of agricultural production, total cultivated land area, head of household, farming time, and farming terms affected farmer demand for agricultural insurance. Research on factors influencing agricultural insurance supply in China includes the following. Tian (2004) 
recognized the factor influencing the Chinese agricultural insurance supply as a problem of market failure; the cause of market failure was the government playing a leading role in the industry's operation mode, namely, the operation of the agricultural insurance policy supply. Thus, he believed that under certain conditions, some types of commercial insurance operations could improve the supply of agricultural insurance coverage levels in China. According to the characteristics of agricultural insurance operation, content, systems, and policies of micro supply, Tuo (1996) divided the mode of foreign agricultural insurance into four types: the American model, the Japan model, the model of Western Europe, and the model of other developing countries in Asia. He then analyzed the characteristics and applicability of each agricultural insurance supply mode separately in terms of content, systems, policies, and other aspects.

In summary, existing research mainly analyzes the demand for agricultural insurance from an adverse selection and moral hazard risk point of view or the influencing factors on agricultural insurance supply in terms of the operational mode, without taking into account other factors; domestic research in China focuses more on micro data, influencing factors for agricultural insurance from the perspective of risk preference, household economic characteristics, social characteristics and other personal exploration; these studies prove very useful references of significance in this study. However, notably, trying to improve the level of agricultural insurance guarantees from the supply or demand side alone has little effect. We have to do both at the same time, and raise the issue of agricultural insurance coverage beyond these two dimensions. Therefore, from the point of view of supply and demand, it is of theoretical and practical significance to study the factors that affect the issues of agricultural insurance guarantees in China as a whole.

This study investigates the factors influencing agricultural insurance coverage levels in China from the dimensions of supply and demand. The aim is to understand the relationship between the various factors and the level of agricultural insurance protection by assessing "the balance of supply and demand" needed to control these factors. The study focuses on the needs of agricultural management, the government, and insurance companies on the supply side. Based on the results of previous studies, economic analysis principles and references are utilized to identify the factors influencing the demand and supply sides through qualitative and quantitative calculations, analysis of the factors direction and influence. This paper puts forward some feasible proposals for the supply and demand balance in China's agricultural insurance, which will be beneficial to enhancing the coverage levels of agricultural insurance in the future.

\section{Methodology}

\subsection{Qualitative Analysis: the Influencing Factors}

\subsubsection{Qualitative Analysis Factors Affecting Demand}

According to theoretical analysis and previous research, the factors that affect the demand for agricultural insurance are as follows.

Macro-level: Agricultural economic development

Social and economic development level

The development level of the social economy is the economic context of the development of the agricultural insurance industry and the relationship between these two, can be described as "a rising river, lifts all boats" and "if one of two interdependent things fail, all others are in danger." When the economic situation is in a rapid development stage, the insurance industry will develop rapidly as well, which means more types of product and service quality that promote the industry's upgrade progress; on the other hand, if the economic situation falters, with inflation and unemployment rising, and income levels plummeting, the agricultural insurance industry will be unable to rebound after such a fall, and consumer demand for agricultural insurance will be impossible.

In quantitative calculations, the "per capita GDP” represents the social and economic development level of that year. GDP refers to the value of all final products and services produced in a country or region in a given period of time (quarter or year) (Gao et al. 2007). The higher the per capita GDP, the greater the value of per capita final products produced by the use of production factors in the region, thereby, reflecting the degree of socio-economic development in the region. 
Stage of agricultural development

Even with the same degree of economic development, different countries at different agricultural development stages will have different agricultural insurance development strategies. Therefore, the levels of agricultural insurance coverage will not be the same, and the consumer demand for agricultural insurance will be influenced by such factors.

Indicators that can be used to represent stages of agricultural development are per capita agricultural GDP or urbanization rates (the proportion of urban population to total population). According to the "per capita GDP" of the social and economic development level, the "per capita agricultural GDP” may be co-linear, and can be tested in the subsequent regressions. Macroeconomics states that a high urbanization rate accounts for the proportion of the population in cities, and that the higher the level of economic development and agriculture, thus, in a more advanced stage, the urbanization rate can be used as an index to measure agricultural insurance demand.

Micro-level: Individual characteristics of agricultural management

(1) Economic characteristics: income level, the proportion of agricultural income to total income, loan status, cultivated land area or number of farms, and degree of specialization in agricultural management, among others;

(2) Social characteristics: gender, age, years farming, and education level, among others;

(3) The degree of risk preference: the magnitude of the impact of natural disasters, and the expected risk, among others.

Considering the availability of data and computational convenience, the above factors can be represented by the following indicators: the level of farmers' per capita net income; percentage of farm income out of total income; the agricultural added value accounting for the proportion of GDP; the per capita arable land area of crop sowing; and the natural disasters, and size of disaster areas. Among them, some indicators need a sample investigation, such as the agricultural management loans, the degree of specialization, gender, age, years of farming, education level, and the expected risk level, to see whether or not these may be indicators in the quantitative calculation model.

\subsection{Qualitative Analysis of the Factors Affecting Supply}

As a policy insurance, agricultural insurance has the characteristics of asymmetric information, being a quasi-public good, and having positive externalities. In addition to the business insurance companies, the government also plays an indispensable role in this marketplace. Considering the factors that affect the supply of agricultural insurance, we can start with the government and insurance companies, and the following factors.

(1) Government: government subsidies, whether or not insurance is compulsory, legislation, and the government position (leading or assisting), among others;

(2) Insurance companies: premiums, service levels, types of insurance products, insurance institutional attributes (public or private), and compensation, among others.

Considering the availability of data and the convenience of calculation, the above factors can be represented by the following indicators.

The amount of government subsidies: government subsidies for agricultural insurance; legislation: the dummy variable equals 1 if there is legislation and 0 otherwise; the price of insurance: premiums; insurance products: number of agricultural insurance product categories; and insurance claim payments: agricultural insurance compensation. Among them, the indicators that are difficult to include in the quantitative calculation are: whether or not the insurance is compulsory, government positioning, the service level of insurance companies, and the public or private attributes of insurance institutions. The source for data on agricultural insurance coverage levels is the Report of Agricultural Insurance Coverage Level in China during 2008 - 2015. In the past few years, the three industry constituents, the central government, the local governments, and farmers, paid premiums of 50\%, $30 \%$, and $20 \%$, respectively. The four difficult to quantify indicators have not impacted insurance policies and thus, are not included in the quantitative calculation in the model. Therefore, the dependent variable in the agricultural insurance guarantee supply model is the level of agricultural insurance guarantees in China; there are five independent variables in the model, namely, government subsidies, legislation, insurance prices, insurance products, and insurance claims. 


\subsection{Quantitative Analysis: the Influencing Factors}

\subsubsection{Quantitative Analysis: the Factors Affecting Demand}

The following are the elements of the agriculture demand model and the sources of the data.

Y: Agricultural insurance coverage level in China

Data are collected from The report of Agricultural Insurance Coverage Level in China issued every year in the period 2008 - 2015.

X1: The level of social and economic development

Data of “per capita GDP” from the World Bank released for the years 2008 - 2015, including Chinese GDP (current price of U.S. dollars) and the population.

$\mathrm{X} 2$ : Stage of agricultural development

Using the "per capita agricultural GDP" or "urbanization rate," the data were from the World Bank issued for the years 2008 - 2015 regarding agricultural added value, the agricultural population, and the proportion of urban population to the total population.

X3: Income level

Using the "per capita net income of farmers," the data came from the Agricultural Research Center of the Ministry of Agriculture.

$\mathrm{X} 4$ : The proportion of agricultural income

Using World Bank data, the proportion of agricultural added value to GDP was captured.

X5: Cultivated land area

The sown area of planting from the National Agricultural Statistics Summary was used.

X6: The effects of natural disasters

The data were captured in the "disaster area" statistics in the Chinese Rural Statistical Yearbook.

By constructing a Cobb Douglas production function, the regression analysis of the factors affecting agricultural insurance demand was carried out. The model is as follows:

$$
\mathrm{Y}=\mathrm{A} \cdot \mathrm{X}_{1}^{\alpha 1} \cdot \mathrm{X}_{2}^{\alpha 2} \cdots \cdots \mathrm{X}_{n}^{\alpha n}
$$

where $n$ is the number of factors affecting the demand for agricultural insurance. We transform (1) to arrive at formula (2):

We transform (2) to arrive at formula (3):

$$
\ln \mathbf{Y}=\boldsymbol{C}+\sum \boldsymbol{\alpha}_{\mathbf{i}} \ln \mathbf{x}_{\mathbf{i}}, \mathrm{i}=1,2,3 \cdots \cdots \mathrm{n}
$$

$$
\ln Y=C+\alpha_{1} \ln x_{1}+\alpha_{2} \ln x_{2}+\alpha_{3} \ln x_{3}+\alpha_{4} \ln x_{4}+\alpha_{5} \ln x_{5}+\alpha_{6} \ln x_{6}
$$

Regression analysis was carried out by Stata13.0 software. First, using a stepwise regression method to determine whether multicollinearity exists, regardless of the use of agricultural GDP per capita or urbanization rate as the $\mathrm{x} 2$ variable in the model calculation, "t" values are not appropriate, $\mathrm{R} 2$ and adjusted $\mathrm{R} 2$ are smaller, so the variables $\mathrm{x} 2, \mathrm{x} 4$, and $\mathrm{x} 6$ are excluded in the analysis; the $\mathrm{p}$ value is greater than 0.5 , and obviously significance is difficult, eliminating both tests. Furthermore, the least squares regression is used to eliminate heteroscedasticity and the absolute value of weighted residuals is obtained. The model fitting results are shown in Table 1.

TABLE 1 . The regression analysis of the demand factors influencing agricultural insurance coverage levels

\begin{tabular}{rrrrr}
\hline Source & SS & df & MS & Number of obs. $=8$ \\
\hline Model & .975544993 & 3.325181664 & Prob $>$ F $=0.0004$ \\
Residual & .014561167 & 4.003640292 & R-squared $\quad=0.9853$ \\
& & Adj R-squared $=0.9743$ \\
Total & .990106159 & 7.141443737 & Root MSE $=.06033$ \\
\hline
\end{tabular}

$$
\mathrm{y} \text { Coef. Std. Err. } \quad \mathrm{t} \quad \mathrm{P}>|\mathrm{t}| \quad[95 \% \text { Conf. Interval }]
$$

$\begin{array}{rllllll}\mathrm{x}_{1} & 1.147553 & .3202798 & 3.58 & 0.023 & .258314 & 2.036793 \\ \mathrm{X}_{3} & -.8722144 & .5502555 & -1.59 & 0.188 & -2.399969 & .6555399 \\ \mathrm{X}_{5} & .7297565 & .2680022 & 2.72 & 0.053 & -.0143369 & 1.47385 \\ \mathrm{C}_{\text {Cons }} & -.052629 & .0385285 & -1.37 & 0.244 & -.1596012 & .0543433\end{array}$


In the regression analysis, we can see from Table 1 the following. The goodness of fit and adjusted goodness of fit are 0.985 and 0.974 , respectively; the goodness of fit is close to 1 and through the $\mathrm{F}$ test, there is a better model fitting effect; $\mathrm{x} 1$ is significant at the $5 \%$ level, and the elastic coefficient of direction is positive. Among the many influential factors, the social and economic development level is the most important, namely, the higher the degree of economic development, the more demand for agricultural insurance. In the analysis of the factors, when GDP per capita increases, this indicates that there is a good economic development situation, and farmers increase their expectations of agricultural output value and their enthusiasm for farming along with an increase in their disposable income. At the same time, for the farmers to avoid the risk of natural disasters, agricultural insurance can be used to effectively disperse and transfer the risk of agricultural production, and to more efficiently resist agricultural losses; thus, farmers will increase input into agricultural insurance; $x 5$ is significant at the $10 \%$ level, and the elastic coefficient of the direction is positive, which shows the greater the scale of production, the more risk averse the farmers are; in such a case, a disaster may cause them a huge economic cost, so they tend to choose agricultural insurance as a means of spreading risk, avoiding any personal commitment to large-scale economic losses. Thus, for new agricultural business entities representing a larger number of farms, versus individual peasant planting areas, these have a correspondingly larger agricultural insurance demand; the x3 p value at the 10\% level is not significant, but compared to the other three variables, when excluded, is significantly higher. The coefficient of elasticity is negative, indicating that the direction of income is in opposition with the demand direction. The higher the income of the farmers, the stronger their ability to control agricultural risk, and the weaker their risk aversion; in such as case, they are more willing and have the ability to take a self-insurance approach to agricultural production, and thus there is less motivation to purchase agricultural insurance to reduce risk.

\subsection{Quantitative Analysis of the Factors Influencing Supply}

The following are the elements of the agriculture supply model and the sources of the data.

Y: Agricultural insurance coverage level in China

Data are collected from The Report of Agricultural Insurance Coverage Level in China issued every year in the period 2008 - 2015.

X1: Government subsidies

Captures the amount of government premium subsidies, with the data derived from the Statistics Table of Policy Agricultural Insurance issued by the China Insurance Regulatory Commission in the years of 2008 - 2015.

\section{$\mathrm{X} 2$ :Legislation}

A dummy variable is created that equals 1 if there is legislation and 0 otherwise. On October 24, 2012, the State Council declared the "Agricultural Insurance Ordinance" as the dividing line.

X3: Insurance price

For the insurance companies' premium income, with the data derived from the Statistics Table of Policy Agricultural Insurance issued by the China Insurance Regulatory Commission in the years 2008 - 2015.

$\mathrm{X} 4$ : Type of insurance products

Based on the category "agricultural insurance business type," with the data derived from the Statistics Table of Policy Agricultural Insurance issued by the China Insurance Regulatory Commission in the years 2008 - 2015.

X5: Insurance payment

Capturing the amount of compensation paid out through agricultural insurance, with the data derived from the Statistics Table of Policy Agricultural Insurance issued by the China Insurance Regulatory Commission in the years 2008 - 2015.

By constructing a Cobb Douglas production function, a regression analysis of the factors affecting agricultural insurance supply was performed. Thus, the model is as follows:

$$
\mathrm{Y}=\mathrm{A} \cdot \mathrm{X}_{1}^{\alpha 1} \cdot \mathrm{X}_{2}^{\alpha 2 \cdots \cdots \cdot \mathrm{X}_{n}^{\alpha n}}
$$

where $\mathrm{n}$ is the number of factors affecting the supply of agricultural insurance. We transform (4) to arrive at formula (5):

$$
\ln \mathbf{Y}=C+\sum \alpha_{\mathbf{i}} \ln \mathbf{x}_{\mathbf{i}}, \mathrm{i}=1,2,3 \cdots \cdots \cdot \mathrm{n}
$$


We transform (5) to arrive at formula (6):

$$
\ln Y=C+\alpha_{1} \ln \mathrm{x}_{1}+\alpha_{2} \mathrm{D}+\alpha_{3} \ln \mathrm{x}_{3}+\alpha_{4} \ln \mathrm{x}_{4}+\alpha_{5} \ln \mathrm{x}_{5}
$$

Regression analysis was carried out by Stata13.0 software. First, using a stepwise regression method to determine whether there is multicollinearity; examining $\mathrm{Y}$ and each variable regression analysis, with $\mathrm{Y}$ and $\mathrm{X} 1$ in the regression, we choose $\mathrm{Y}$ and $\mathrm{X} 1$ with the best goodness of fit as the initial model. When the dummy variable is added, D2 is ignored because of multicollinearity, so the dummy variable cannot be added to the model. The linear combination follows by adding the three variables X3, X4, and X5 into the model; the calculation of either R2 and adjusted R2 then becomes smaller, and it is difficult to pass the test of significance, so we remove these three variables. Furthermore, the least squares regression is used to eliminate heteroscedasticity and the absolute value of weighted residuals is obtained. The model fitting results are shown in Table 2.

Table 2. The regression analysis of factors influencing supply of agricultural insurance coverage

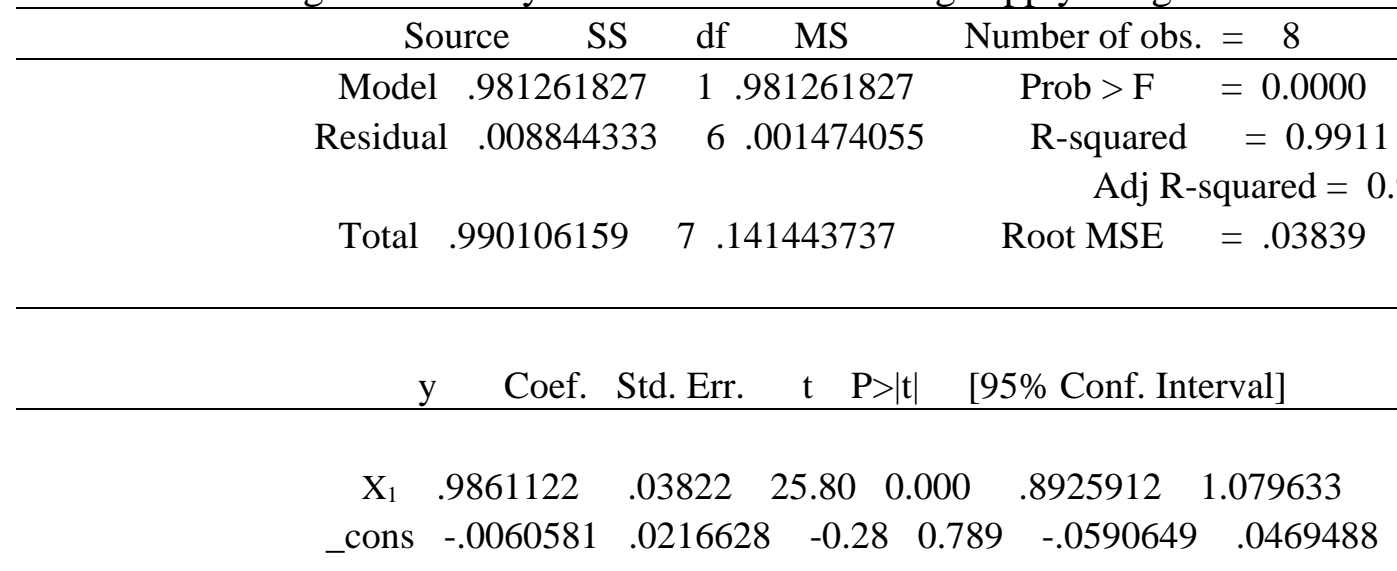

In the regression analysis, we can see in Table 2 the following. The goodness of fit and adjusted goodness of fit are 0.991 and 0.989 , respectively; the goodness of fit is close to 1 , and through the F test, the better model fitting effect is shown; X1 is significant at the $1 \%$ level, and the elastic coefficient of direction is positive, indicating that government agricultural insurance subsidy is the most important factor. The reasons behind this are: first, the higher the proportion of government premium subsidies, the smaller the premiums required from the farmers; second, as agricultural insurance risk is decentralized, production cost moves lower; third, the insurance companies' profits are enhanced and this added reliability and stability encourages them to provide more agricultural insurance products; and finally, with smaller premiums, farmers with different risk preferences are more willing to participate in agricultural insurance.

\section{Results and Discussion}

In sum, based on an analysis of the principles of demand economics and domestic and foreign research results, first, the factors influencing agricultural insurance demand from a macro and a micro perspective are qualitatively identified; subsequently, from a quantitative point of view, the dependent and independent variables are chosen for the regression analysis; the agricultural insurance coverage is selected as the dependent variable; the per capita GDP, per capita agricultural GDP or urbanization rate, per capita net income of farmers, farmers income accounting for the proportion of the total income, farmers planting acreage, and crop disaster area are the six representative indicators and the independent variables. Through the quantitative analysis, the conclusion is that the level of social and economic development and the scale of rural production have the most positive significant impact on agricultural insurance demand, and the per capita net income of farmers has the most negative significance.

As with our analysis of demand, on the supply side, the analysis is also based on economics principles and domestic and foreign research results. First, the qualitative factors are identified that may affect agricultural insurance supply from a government and insurance company perspective; subsequently, from a quantitative point of view, the dependent and independent variable are chosen. 
The level of agricultural insurance coverage is selected as the dependent variable; the premium subsidy amount, legislation, insurance company premium income, agricultural insurance types, and agricultural insurance compensation are the five representative indicators and the independent variables in the regression analysis. Through quantitative analysis, we conclude that the amount of the government premium subsidy is the most significant factor affecting guaranteed agricultural insurance supply, and the larger the subsidy amount and proportion, the more it promotes the supply of agricultural insurance.

In order to achieve the balance between the supply and demand of agricultural insurance, the two dimensions should be considered comprehensively. First, neither the supply side nor the demand side of agricultural insurance can be divorced from its social economic context as China tries to create a strong environment for the development of agricultural insurance and thereby, strengthen the national economy. Second, on the supply side, the role of the government rather than that of business insurance companies is significantly greater for agricultural insurance policies as government subsidies for premiums have the most direct effect on agricultural insurance and are able to mobilize agricultural insurance companies, thereby increasing supply. Thus, in the agricultural insurance industry, the government plays a vital role in Chinese agricultural insurance vis-à-vis insurance companies' business operations. The need for government financial support and supervision is indispensable so that agricultural insurance becomes more stable and sound, and the agricultural insurance supply capacity is enhanced in China. Moreover, in the promotion of agricultural insurance supply capacity, the demand for agricultural insurance also requires a simultaneous corresponding increase to enhance the levels of agricultural insurance coverage in the balance of supply and demand.

The reasons farmers choose agricultural insurance can be divided into two categories; one is whether agricultural insurance risk protection is of use, how farmers manage it, and the role of risk; two is whether farmers want to use agricultural insurance to disperse agricultural production cost risk and lower their risk versus their own measures to disperse production cost risks. For the scale of the production and operation of large agricultural enterprises, the law of large numbers reflects the possibility of suffering losses based on these numbers and scale; farmers with more risk buy agricultural insurance to avoid their own risk; so new agricultural business entities rather than retail farmers are the main audience of agricultural insurance. This context is similar to Freedman's conclusion of absolute risk aversion. When the economic strength of the insured becomes stronger, the ability of self-avoiding risk is also enhanced. As a result, the desire to buy insurance weakens, and the preference for self-insurance is more pronounced. The income level of farmers is negatively correlated with the willingness to buy agricultural insurance. When farmers per capita net income accounts for a larger proportion of agricultural production and operation, they become more important, and there is a risk that they will have more experience in agriculture and more economic ability to bear the consequences of natural disasters on production; in this situation, risk preferences may become more inclined to self-insurance measures for the management of risk rather than the purchase of agricultural insurance. Therefore, the higher the income of farmers, the smaller the demand for agricultural insurance; to develop corresponding insurance products for this group, improving the level of protection of agricultural insurance in China can be considered, which would enhance the level of protection on the demand side.

\section{Conclusion}

This paper analyzes agricultural insurance in terms of both supply and demand from the perspectives of the government, the business insurance companies, and the farmers in the period of 2008-2015. The main factors affecting agricultural insurance coverage in China are: the extent of local social economic development, the scale of agricultural production, farming income, and government premium subsidies. In order to enhance levels of both supply and demand, the government should increase financial subsidies, and actively cooperate with business insurance companies in launching a variety of insurance products and services to enhance farmers' insurance options and risk prevention and thereby, jointly improve the levels of agricultural insurance coverage. 


\section{Acknowledgments}

This paper was financially supported by the "12th Five-Year Plan" of China (2014BAL07B03.2). We are grateful to Dr. Zhang Qiao , Dr. Wang Ke and Dr.Zhao Sijian of the Agricultural Information Institute of the Chinese Academy of Agricultural Science for comments on the manuscript.

\section{References}

[1]. Chen Y, Ling Y Y, Chen Z Y, Zheng Y L. 2007. Agricultural Insurance Purchase Intention: An Empirical Study of Influencing Factors. Journal of Agricultural Economics, 6(2): 26-30.

[2]. Gao H. 2007. Western Economics (the fourth edition). Renmin University of China Press. (in Chinese)

[3]. Jiang F. 2012. The Empirical Analysis of the Influencing Factors of Supply and Demand of Agricultural Insurance in China. Anhui Agricultural University, 34-38. (in Chinese)

[4]. Just R E, Calvin L, Quiggin J. 1999. Adverse Selection in Crop Insurance. American Journal of Agricultural Economics, 81(4), 834-49.

[5]. Li L, Wang J. 2010.An Empirical Analysis of the Agricultural Insurance Willingness to SpendBased on the Field Survey in HeBeing Province. Financial Theory \& Practice,7(3),19-22.

[6]. Liu X T. 2014. Analysis on Influencing Factors of Engineering Insurance Demand. Southwestern University of Finance and Economics,114-128. (in Chinese)

[7]. Ning M X, Xing L, Zhong F N. 2005. Factors Influencing Xinjiang Farmers' Decisions to Purchase Crop Insurance: A Case Study on Manas Valley. Issues in Agricultural Economy, 6(1) 38-45.

[8]. Shaik S, Coble K H, Knight T O. 2005. Revenue Crop Insurance Demand. In selected paper presented at AAEA Annual Meeting, Providence, Rhode Island, July 24-27.

[9]. Smith A 1972. The Wealth of Nations. First chapter 10, the Commercial Press. 337-356.

[10]. Sun S L. 2009. Study on the Problems of Agricultural Insurance Supply in China. Technology and Business University, 71-76. (in Chinese)

[11]. Tian S B. 2004.The Analysis of the Causes of the Shortage of Commercialization of Agricultural Insurance in Our Country. Review of Economic Research, (87) 23-24.

[12]. Tuo G Z. 1996. Foreign Agricultural Insurance Development Pattern, the Background and Policy. China Rural Survey, 6(2) 26-31, 64. (in Chinese)

[13]. Wang W, Tian J, Du J, Li J P. 2010. Policy-oriented Agricultural Insurance Pilot Provinces Ginseng Protect Farmers Intend to Empirical Research-Based on the Survey in HeNan Province. Financial Theory \& Practice, 10 (1), 37-41.

[14]. Wright B D, Hewitt J D. 1990. All Risk Crop Insurance: Lessons From Theory and Experience, California Agricultural Experiment Station, 4(1),63-77.

[15]. Zhang W Y. 1997. James Morris Article Selected Under the Asymmetric Information of Incentive Theory. The Commercial Press, 199-207.

[16]. Zhang Y H, Gu H Y, Shi Q H. 2005. One Explanation on the Lacking Demand of

[17]. Agricultural Insurance from the View of Utility. The Journal of Quantitative \&Technical Economics, 22(4):83-92. 
[18]. Zhang Q, Wang K, Li Y. 2017. The Report of Chinese Agricultural Insurance Coverage Level. Agricultural Information Institute of Chinese Academy of Agricultural Science,18-19. (in Chinese) 